\title{
Dopaminergic Neurons Exhibit an Age-Dependent Decline in Electrophysiological Parameters in the MitoPark Mouse Model of Parkinson's Disease
}

\author{
Sarah Y. Branch, ${ }^{1}$ Cang Chen, ${ }^{2}$ Ramaswamy Sharma, ${ }^{3}$ James D. Lechleiter, ${ }^{3}$ Senlin Li, ${ }^{2,4}$ and Michael J. Beckstead ${ }^{1,4}$ \\ Departments of ${ }^{1}$ Physiology, ${ }^{2}$ Medicine, ${ }^{3}$ Cellular and Structural Biology, and ${ }^{4}$ Center for Biomedical Neuroscience, University of Texas Health Science \\ Center, San Antonio, Texas 78229
}

\begin{abstract}
Dopaminergic neurons of the substantia nigra (SN) play a vital role in everyday tasks, such as reward-related behavior and voluntary movement, and excessive loss of these neurons is a primary hallmark of Parkinson's disease (PD). Mitochondrial dysfunction has long been implicated in PD and many animal models induce parkinsonian features by disrupting mitochondrial function. MitoPark mice are a recently developed genetic model of PD that lacks the gene for mitochondrial transcription factor A specifically in dopaminergic neurons. This model mimics many distinct characteristics of PD including progressive and selective loss of SN dopamine neurons, motor deficits that are improved by L-DOPA, and development of inclusion bodies. Here, we used brain slice electrophysiology to construct a timeline of functional decline in SN dopaminergic neurons from MitoPark mice. Dopaminergic neurons from MitoPark mice exhibited decreased cell capacitance and increased input resistance that became more severe with age. Pacemaker firing regularity was disrupted in MitoPark mice and ion channel conductances associated with firing were decreased. Additionally, dopaminergic neurons from MitoPark mice showed a progressive decrease of endogenous dopamine levels, decreased dopamine release, and smaller D2 dopamine receptor-mediated outward currents. Interestingly, expression of ion channel subunits associated with impulse activity (Cav1.2, Cav1.3, HCN1, Nav1.2, and NavB3) was upregulated in older MitoPark mice. The results describe alterations in intrinsic and synaptic properties of dopaminergic neurons in MitoPark mice occurring at ages both before and concurrent with motor impairment. These findings may help inform future investigations into treatment targets for prodromal PD.
\end{abstract}

Key words: dopamine; electrophysiology; mice; MitoPark; neurotransmission; Parkinson's

Significance Statement

Parkinson's disease (PD) is the second most diagnosed neurodegenerative disorder, and the classic motor symptoms of the disease are attributed to selective loss of dopaminergic neurons of the substantia nigra. The MitoPark mouse is a genetic model of PD that mimics many of the key characteristics of the disease and enables the study of progressive neurodegeneration in parkinsonism. Here we have identified functional deficits in the ion channel physiology of dopaminergic neurons from MitoPark mice that both precede and are concurrent with the time course of behavioral symptomatology. Because PD is a progressive disease with a long asymptomatic phase, identification of early functional adaptations could lay the groundwork to test therapeutic interventions that halt or reverse disease progression.

\section{Introduction}

Parkinson's disease (PD) is the second most diagnosed neurodegenerative disorder and places an enormous economic and social

Received April 10, 2015; revised Feb. 8, 2016; accepted Feb. 26, 2016.

Author contributions: S.Y.B., J.D.L., S.L., and M.J.B. designed research; S.Y.B., C.C., and R.S. performed research; S.Y.B., R.S., and M.J.B. analyzed data; S.Y.B., R.S., S.L., and M.J.B. wrote the paper.

This work was supported by grants from the William and Ella Owens Medical Research Foundation (M.J.B.), National Institutes of Health R01 Grant DA32701 (M.J.B.), a pilot grant (M.J.B.) through the (enter for Biomedical Neuroscience/National Center for Advancing Translational Sciences, National Institutes of Health through Grant UL1 TR001120, and a Merit Review Grant from the Veterans Health Administration (to S.L.). The content is solely the responsibility of the authors and does not necessarily represent the official views of the NIH. We thank Dr Amanda Sharpe for valuable assistance with the immunostaining. burden on society. Excessive loss of dopaminergic neurons of the substantia nigra $(\mathrm{SN})$ is the primary hallmark of $\mathrm{PD}$ and is responsible for the motor impairments of the disease (Hornykiewicz, 1975; Dauer and Przedborski, 2003). Although PD often goes undiagnosed until the appearance of overt motor impair-

\section{The authors declare no competing financial interests.}

Correspondence should be addressed to either of the following: Michael Beckstead, UTHSCSA Department of Physiology, MSC 8253, 7703 Floyd Curl Drive, San Antonio, TX 78229, E-mail: beckstead@uthscsa.edu; or Senlin Li, UTHSCSA Department of Medicine, MSC 7881, 7703 Floyd Curl Drive, San Antonio, TX 78229, E-mail: Lis1@uthscsa.edu.

DOI:10.1523/JNEUROSCI.1395-15.2016

Copyright $\odot 2016$ the authors $\quad 0270-6474 / 16 / 364026-12 \$ 15.00 / 0$ 
ment, functional adaptations may occur early in disease progression and could contribute to symptom manifestation at later stages. Motor impairment is not typically seen until dopaminergic neuron loss reaches 50-60\%, suggesting that compensatory mechanisms may mask disease pathology for years before diagnosis (de la Fuente-Fernández et al., 2011). Current PD treatments do not alter disease progression and instead focus on the relief of symptoms such as bradykinesia and resting tremor. A better understanding of the progressive cellular events that preempt the outward appearance of behavioral symptoms will be critical for the development of more effective treatments.

Although the exact causes of PD are highly debated, the disease may be attributed to a combination of factors including mitochondrial dysfunction, oxidative stress, protein mishandling, and genetic disposition (Greenamyre and Hastings, 2004). Toxin and genetic mouse models typically used to study PD demonstrate disrupted mitochondrial function which can lead to some, but not all, of the cardinal features of PD (Schober, 2004; Goldberg et al., 2005; Kitada et al., 2007; Terzioglu and Galter, 2008; Lin et al., 2009; Dawson et al., 2010; Duty and Jenner, 2011). A genetic mouse model of PD termed MitoPark has recently been developed that mimics many of the distinct characteristics of the disease including progressive and selective loss of SN dopamine neurons, preferential loss of SN dopamine neurons over that of the ventral tegmental area, spontaneous horizontal and vertical locomotor deficits that are improved for a time with L-DOPA treatment, decreased monoamine levels in the striatum, cognitive impairment preceding motor impairment, and development of inclusion bodies (Ekstrand et al., 2007; Galter et al., 2010; Li et al., 2013). The MitoPark mouse lacks mitochondrial transcription factor A (Tfam) specifically in dopaminergic neurons which leads to development of severe respiratory chain deficiency and faithfully reproduces key parkinsonian features (Larsson et al., 1998; Ekstrand and Galter, 2009).

MitoPark mice lack overt phenotypes early in life but as adults develop parkinsonian symptoms in a progressive manner that mimics the time-dependent decline observed in human PD. These mice first exhibit impaired spatial learning at 8 weeks, decreased locomotion at 8-14 weeks, increased acoustic startle at 15-20 weeks, and decreased body weight at 16-20 weeks (Ekstrand et al., 2007; Li et al., 2013; Grauer et al., 2014). Interestingly, dopaminergic neurons from 6- to 8-week-old MitoPark mice exhibit altered firing patterns, decreased dopamine release, and decreased hyperpolarization-activated cyclic nucleotidegated (HCN) channel function (Good et al., 2011), suggesting that functional adaptations occur in single neurons before the overt motor impairment. No study to date has investigated progressive changes in ion channel conductances across different ages in MitoPark mice, which likely reflect both functional decline and adaptation. Because PD in humans has a long asymptomatic phase, knowledge of early functional adaptations could lead to development of better treatment strategies that slow, halt, or reverse disease progression.

In this study, we used patch-clamp electrophysiology and quantitative RT-PCR to investigate individual ion channel conductances, as well as components of dopamine neurotransmission in MitoPark and control mice. Our results identify multiple examples of declining functionality in single neurons across a range of ages. We also observed increased mRNA expression of ion channel subunits that are associated with spontaneous firing, indicating adaptive changes in gene expression concurrent with neurodegeneration.

\section{Materials and Methods}

Animals. MitoPark mouse breeding pairs were obtained from Dr NilsGöran Larsson (Karolinska Institute, Stockholm, Sweden; now at Max Planck Institute for Biology of Aging, Cologne, Germany). To generate experimental MitoPark mice and non-MitoPark littermate controls, the DAT $^{\text {cre }}$ and $\mathrm{Tfam}^{\operatorname{lox} P}$ mouse strains were first backcrossed to C57BL/6J mice (The Jackson Laboratory), and offspring were selectively mated to generate double-heterozygous males $\left(\mathrm{DAT}^{+/ \text {cre }} ; \mathrm{Tfam}^{+/ \text {loxP }}\right.$ ) and homozygous floxed Tfam females $\left(\mathrm{DAT}^{+/+} ; \mathrm{Tfam}^{\operatorname{loxP} / \text { loxP }}\right)$. The doubleheterozygous males were then crossed to homozygous $\mathrm{Tfam}^{\text {loxP/loxP }}$ females, yielding $25 \%$ MitoPark mice (DAT ${ }^{+/ \text {cre }}$; Tfam $^{\text {loxP } / \text { loxP }}$ ) and $25 \%$ littermate controls $\left(\mathrm{DAT}^{+/+} ;\right.$Tfam $\left.^{\text {loxP/loxP }}\right)$. Mice were group-housed in same-sex, standard shoebox cages with a ventilated caging system and ad libitum access to food and water. Male mice were used for all experiments except for RT-PCR studies in which male and female tissue was used. The room was maintained at $26^{\circ} \mathrm{C}$ on a $12 \mathrm{~h}$ light/dark light cycle. All animal care and use was in accordance with the Guide for the Care and Use of Laboratory Animals, National Research Council, and approved by the Institutional Animal Care and Use Committee at the University of Texas Health Science Center at San Antonio.

Genotyping. DNA was extracted from mouse tail tip by digestion in buffer containing $10 \mathrm{~mm}$ Tris- $\mathrm{HCl}, 50 \mathrm{~mm} \mathrm{KCl}$, and $0.1 \%$ Tween 20 with proteinase $\mathrm{K}$ solution $(0.2 \mathrm{mg} / \mathrm{ml})$, incubated at $55^{\circ} \mathrm{C}$ overnight. Samples were centrifuged at $15,000 \times \mathrm{g}$ for $20 \mathrm{~min}$ and supernatant was collected as DNA extract. PCR was performed on $0.5 \mu \mathrm{g}$ of DNA. To identify the $\mathrm{DAT}^{+/ \text {cre }}$ genotype, two primer pairs were used. Forward primer sequence was $5^{\prime}$ CATGGAATTTCAGGTGCTTGG, and the reverse primer sequences were 5'-CATGAGGGTGGAGTTGGTCAG and 5'-CGCGAACATCTTCAG GTTCT. For the Tfam ${ }^{\text {loxp/loxp }}$ genotype, two primer pairs were also used. The forward primer sequence was 5'-CTGCCTTCCTCTAGCCCGGG, and the two reverse primer sequences were $5^{\prime}$-GTAACAGCAGACAACTTGTG and 5'-CTCTGAAGCACATGGTCAAT. GoTaq Green Master Mix (Promega) was used for a $35 \mathrm{cycle} P C R$ with the following settings: $95^{\circ} \mathrm{C}$ for $30 \mathrm{~s}, 55^{\circ} \mathrm{C}$ for $30 \mathrm{~s}$, and $72^{\circ} \mathrm{C}$ for $45 \mathrm{~s}$. The PCR products were separated by electrophoresis on $2 \%$ agarose gels and were visualized under UV light after ethidium bromide staining. Two bands at 310 and 470 base pairs for $\mathrm{DAT}^{+/ \text {cre }}$ and one band at 437 base pairs for Tfam ${ }^{\text {loxp/loxp }}$ were indicative of MitoPark mice. One band at 310 base pairs for DAT ${ }^{+/+}$(wild-type) and one band at 437 base pairs for Tfam ${ }^{\operatorname{loxp} / l o x p}$ were indicative of control littermates.

Electrophysiology. On the day of the recording mice were anesthetized with isoflurane and euthanized as described previously (Branch and Beckstead, 2012). Brains were resected and mounted on a vibrating microtome (Leica Microsystems) and horizontal slices (200 $\mu \mathrm{m}$ thick) containing the SN were collected. Slices were maintained in artificial CSF (aCSF) plus kynurenic acid and $10 \mu \mathrm{M} \mathrm{MK}-801$ at $34^{\circ} \mathrm{C}$ and continuously bubbled with $95 \% \mathrm{O}_{2} / 5 \% \mathrm{CO}_{2}$. Recordings were performed at $34^{\circ} \mathrm{C}$ under continuous perfusion of aCSF at a flow rate of $2 \mathrm{ml} / \mathrm{min}$.

Dopaminergic neurons of the SN pars compacta were first identified by location and by electrical properties (Branch et al., 2014). Spontaneous firing was measured with either the loose cell attached method using pipettes of 9-10 M $\Omega$ resistance filled with Na HEPES plus $20 \mathrm{~mm} \mathrm{NaCl}$ ( $290 \mathrm{mOsm} / \mathrm{L}, \mathrm{pH} 7.40$ ), or with pipettes of 2.5-4 M $\Omega$ resistance filled with internal solution containing the following (in $\mathrm{mm}$ ): 115 K-methylsulfate, $20 \mathrm{NaCl}, 1.5 \mathrm{MgCl}_{2}$, 10 HEPES, 10 BAPTA, $2 \mathrm{ATP}$, and 0.4 GTP, pH 7.35-7.40, 267-275 mOsm/L, plus $0.2 \%$ neurobiotin (Vector Laboratories) immediately before gaining access to the interior compartment of the cell. Spike width was calculated (in voltage-clamp mode) as the time from the start of the inward current to the peak of the outward current (Ford et al., 2006). Interspike intervals were calculated as the time between spikes, and all recordings exhibited six or more spikes during a $10 \mathrm{~s}$ sweep. Whole-cell patch-clamp recordings were made with pipettes 1.5-4.0 M $\Omega$ resistance using the K-methylsulfate internal solution described above, except that BAPTA was replaced by $0.025 \mathrm{~mm}$ EGTA in experiments measuring afterhyperpolarization currents. Upon gaining electrical access to the interior compartment of the cell, series resistance, cell capacitance, and input resistance were calculated by fitting an exponential to the decaying phase of the response to a $5 \mathrm{mV}$ voltage step. Series resistance was not compensated but was continuously monitored 
throughout the recording. Recordings with a series resistance $<10 \mathrm{M} \Omega$ were used for analysis. Pipettes used for iontophoresis $(\sim 180 \mathrm{M} \Omega)$ were filled with dopamine $(1 \mathrm{M})$. A backing current of $30-40 \mathrm{nA}$ was applied to prevent leak and dopamine was ejected as a cation with a pulse of +200 $\mathrm{nA}$. Data were acquired at $50 \mathrm{kHz}$ and filtered at $6 \mathrm{kHz}$ using a Multiclamp 700B amplifier (Molecular Devices). Data were recorded and later examined offline using Axograph X software (www.axograph.com). Dopamine inhibitory postsynaptic currents (IPSCs) were measured as described previously (Branch and Beckstead, 2012) in the presence of neurotransmitter receptor blockers for GABA (100 nм CGP55845, 100 $\mu \mathrm{M}$ picrotoxin), glutamate (10 $\mu \mathrm{M} \mathrm{MK}-801,10 \mu \mathrm{M}$ DNQX), and nicotinic acetylcholine (100 $\mu \mathrm{M}$ hexamethonium).

Immunohistochemistry. After electrophysiological recordings, immunohistochemistry was performed on 200 - $\mu \mathrm{m}$-thick brain slices that had been fixed overnight with $4 \%$ paraformaldehyde. Slices were transferred to a solution of potassium PBS (KPBS) solution until processing. Alternatively, mice were perfused with ice-cold saline, brains were fixed with $4 \%$ paraformaldehyde, and $40 \mu \mathrm{m}$ sections were obtained. These slices were washed in a solution of $0.5 \%$ sodium borohydride for $30 \mathrm{~min}$ at room temperature. All sections were bathed in a $1 \% \mathrm{H}_{2} \mathrm{O}_{2}$ solution for 15-30 min, washed twice with KPBS and blocked with 2-5\% goat serum and $0.3 \%$ Triton X-100 (Sigma-Aldrich) for $1 \mathrm{~h}$. After washing with KPBS, all slices were then incubated for at least $48 \mathrm{~h}$ in primary antibody (rabbit anti-tyrosine hydroxylase (EMD Millipore) at $4^{\circ} \mathrm{C}$. Two-hundred micrometer sections were then exposed to goat anti-rabbit AlexaFluor 594 (Abcam) for $2 \mathrm{~h}$ followed by streptavidin AlexaFluor 488 (Jackson ImmunoResearch Laboratories). Forty micrometer sections were incubated with a secondary antibody (goat anti-rabbit AlexaFluor 488 (Millipore) $+0.3 \%$ Triton X for $2 \mathrm{~h}$. All sections were mounted on gelatin-coated slides and using Prolong Gold antifade reagent (Invitrogen). Images were collected on an Olympus DP72 microscope using Olympus standard cellSens software.

RNA extraction and quantitative real-time PCR. Tissue sections containing the $\mathrm{SN}$ from control and MitoPark mice aged 12 weeks ( $n=8$, female) or $18-22$ weeks ( $n=6$, male and female) were stored in RNAlater at $-80^{\circ} \mathrm{C}$ until use (Qiagen). Tissue was later homogenized using TissueMiser (Fisher Scientific), and RNA was extracted using RNeasy mini Plus kit (Qiagen) according to the manufacturer's instructions. RNA concentration was quantified (Nanodrop Products) and sample quality verified based on 260:280 ratio. Reverse transcription reactions were performed using High Capacity cDNA Reverse Transcription kits (Applied Biosystems). Expression levels were analyzed on an AB 7900 Real Time PCR System (Life Technologies) using Power SYBR Green PCR Master Mix (Applied Biosystems). PCRs were initiated by heating to $50^{\circ} \mathrm{C}$ and then to $95^{\circ} \mathrm{C}$ for $10 \mathrm{~min}$ to activate the polymerase. Forty cycles of denaturation at $95^{\circ} \mathrm{C}$ for $15 \mathrm{~s}$ and annealing/ extension at $60^{\circ} \mathrm{C}$ for $1 \mathrm{~min}$ were performed and fluorescence was measured at the end of each extension step. Expression levels of target genes were normalized to expression of the endogenous reference control gene eEF1 $\alpha 1$ (Sharma et al., 2010) and reported as a ratio with $e \mathrm{EF} 1 \alpha 1$ expression. Reactions were performed in duplicate for each gene with standard curves for each primer set and repeated at least twice. PCR amplification products were checked for single PCR products using melt curves with single dissociation peaks and by separation on agarose gels. PCR was performed using the following primer sets (forward followed by reverse): Scn1a: $5^{\prime}-\mathrm{TC}$ AGAGGGAAGCACAGTAGAC-3', and 5'-TTCCACGCTGATTTGACA GCA-3'; Scn $2 a: 5^{\prime}$-ATTTTCGGCTCATTCTTCACACT-3' and 5'-GGGC GAGGTATCGGTTTTTGT-3'; Scn5a: 5'-ATGGCAAACTTCCTGTTAC CTC-3' and 5'-CCACGGGCTTGTTTTTCAGC-3'; Scn7aA: 5' -TTTG TTCGAGCTAATCACAAGGT- $3^{\prime}$ and $5^{\prime}$-GGCCGTGGTTCAAAGGGAT3'; Scn1b: 5'-GGATTCCGATACCGAGGCTG-3' and 5'-GGTCCACTC CGTGAAGGTTT-3'; Scn $2 b$ : 5' -AGTAAGTACGACGTGTCAGTGA-3' and 5'-AGGGTTGGTAATGTAGCAGTTG-3'; Scn3b: 5'-ATGTGTCCAGGGAGTTTGAGT-3' and $5^{\prime}$-TTCGGCCTTAGAGACCTTTCT-3'; Cacnalc: $5^{\prime}$-CCTGCTGGTGGTTAGCGTG-3' and 5'-TCTGCCTC CGTCTGTTTAGAA-3'; Cacnald: 5'-AGAGGACCATGCGAACGAG-3' and 5'-CCTTCACCAGAAATAGGGAGTCT-3'; Kcnn3: 5'-TGTTG CACTCTTCTCCCACG-3' and 5'-GGTCATTGAGATTTAGCTGGCT3'; Hcn1: 5'-CAAATTCTCCCTCCGCATGTT-3' and 5'-TGAAGAA

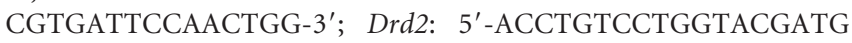

ATG- ${ }^{\prime}$ and $5^{\prime}$-GCATGGCATAGTAGTTGTAGTGG-3'; Efla1: $5^{\prime}$-ATTC-

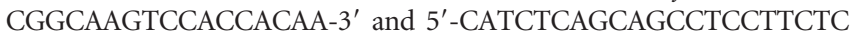
AAAC-3'.

Statistical analysis. Data were analyzed using Prism 6.0 software and are reported as mean \pm SEM. Two-way ANOVAs using repeated measures and Holm-Sidak's multiple-comparison correction were used wherever possible. Linear regressions were used to analyze the relationship between mouse age (in weeks) and measured cellular parameters. $\alpha$ was set a priori at 0.05 for all analyses.

Chemicals. DNQX, picrotoxin, MK-801, kynurenic acid, hexamethonium chloride, GTP, ATP, and ethylene glycol-bis (2, aminoethylether), were purchased from Sigma-Aldrich. CGP 55845 hydrochloride was purchased from Tocris Bioscience. BAPTA tetrapotassium salt was purchased from Invitrogen. Methylsulfuric acid potassium salt was purchased from Acros Organics.

\section{Results}

Basal physiological parameters

Coronal brain slices were obtained from MitoPark mice $\left(\mathrm{DAT}^{+/ \mathrm{cre}}\right.$ $\mathrm{Tfam}^{\text {loxP/loxP }}$ ) and their littermate controls $\left(\mathrm{DAT}^{+/+} \mathrm{Tfam}^{\text {loxP/loxP; }}\right.$ Li et al., 2013), stained for tyrosine hydroxylase and mounted on slides. We observed that the number of tyrosine hydroxylase (TH)positive cells and the extent of staining was visually reduced in aged MitoPark mice (Fig. 1B2) compared with littermate control mice (Fig. 1A1,A2) and younger MitoPark mice (Fig. 1B1).

Acutely isolated horizontal brain slices $(200 \mu \mathrm{m})$ were then obtained for electrophysiological recordings. Dopaminergic neurons of the $\mathrm{SN}$ were first identified by appearance and anatomical location using gradient contrast infrared optics, as well as using accepted electrophysiological parameters. In a later experiment, confirmation was obtained by including $0.2 \%$ neurobiotin in the intracellular recording solution, postfixing slices with $4 \%$ paraformaldehyde, and dual staining for $\mathrm{TH}$ and neurobiotin. The effect of the Tfam knock-out on the electrophysiological properties of SN dopamine neurons was examined. MitoPark mice begin to show locomotor deficits at 12 weeks of age and begin to lose body weight by $\sim 20$ weeks (Li et al., 2013); thus, we obtained electrophysiological recordings both before and during this age range. To more completely assess the effects of the MitoPark mutation across age we analyzed results from individual neurons using both linear regression and ANOVA of data binned by mouse age (even though this occasionally resulted in small sample sizes).

We first used whole-cell patch-clamp electrophysiology to measure basal physiological parameters in dopaminergic neurons. A linear regression analysis was run to assess the association between measured parameters and age (in weeks). Cell capacitance, an indicator of membrane surface area, decreased with age in dopamine neurons from MitoPark mice $\left(R^{2}=0.102, p<\right.$ $0.0001)$, whereas cell capacitance in littermate controls did not significantly change with age $\left(R^{2}=0.0049, p=0.423\right.$; Fig. $\left.1 C\right)$. The slopes of the linear regression lines for MitoPark and controls were significantly different from each other $\left(F_{(1,275)}=14.36 ; p=\right.$ 0.0002 ) indicating an effect of genotype on membrane capacitance across time. When data were organized into bins, two-way ANOVA analysis revealed main effects of genotype and age on cell capacitance (main effect of genotype: $F_{(1,269)}=26.0, p<$ 0.0001 ; main effect of age: $\left.F_{(2,269)}=6.72, p=0.0014\right)$ but no significant age-genotype interaction $\left(F_{(2,269)}=2.242, p=\right.$ 0.1083; Holm-Sidak's multiple-comparisons test, $p<0.01$ for age 6-10 weeks, and $p<0.0001$ for age $16+$ weeks; Fig. 1D). Good et al. (2011) previously described increased input resistance in dopaminergic neurons from 6- to 8-week-old MitoPark mice. We further investigated this effect across age by calculating 
A1

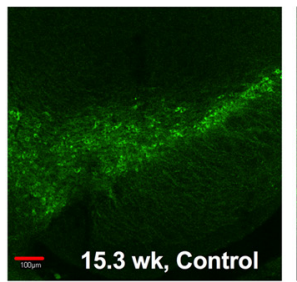

A2

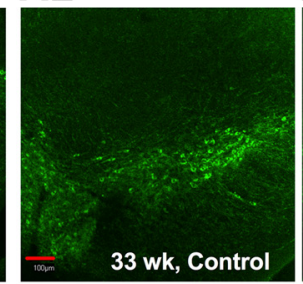

C

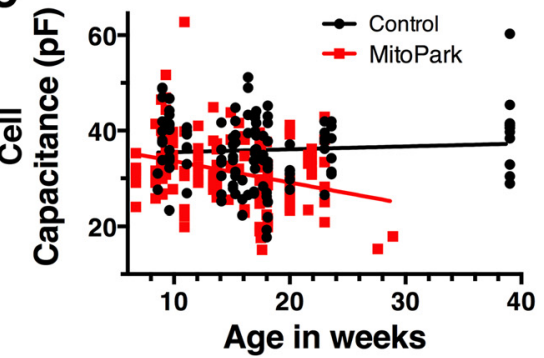

E

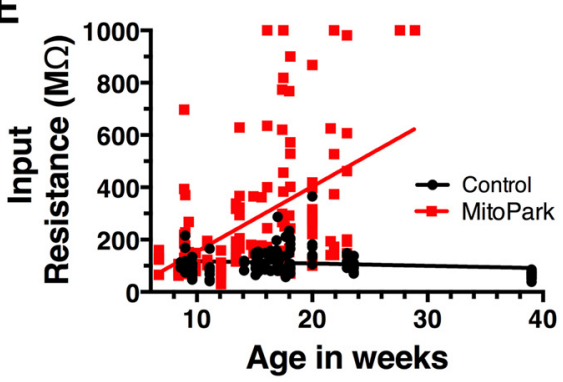

B1

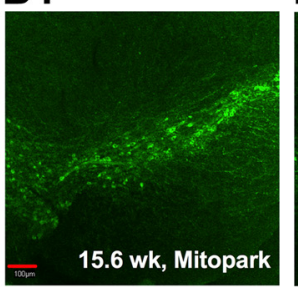

D
D
B2
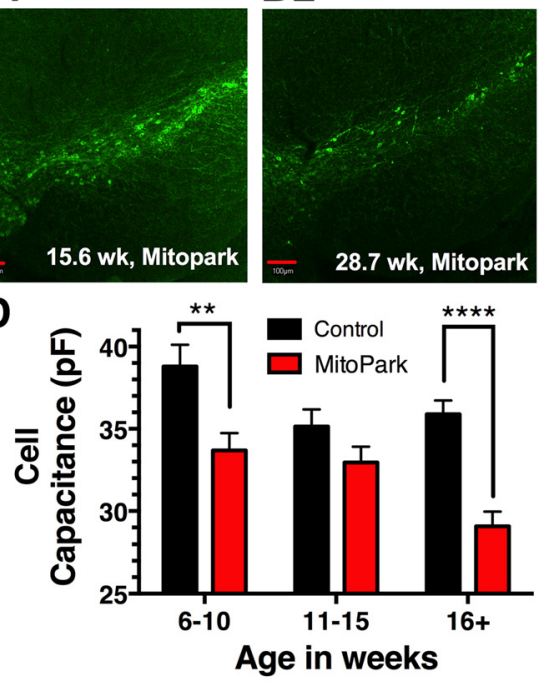

F

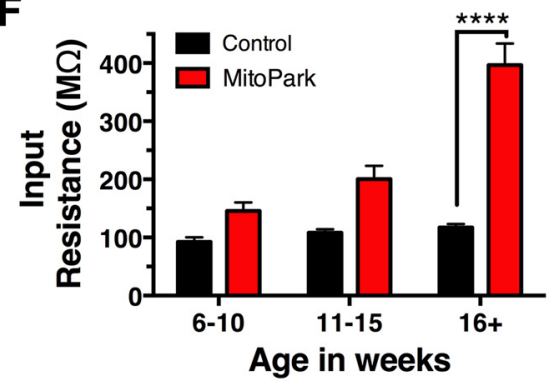

Figure 1. Substantia nigra dopaminergic neurons from MitoPark mice vary in basic electrophysiological parameters. Coronal brain sections from age-matched control $(\boldsymbol{A} 1, \boldsymbol{A} 2)$ and MitoPark $(\boldsymbol{B} 1, \boldsymbol{B} 2)$ mice were stained for TH and images were collected on an Olympus DP72 microscope at $10 \times$ magnification. The sample from the aged MitoPark mouse (B2) exhibited reduced TH immunoreactivity than the other three sections. Scale bars, $100 \mu \mathrm{m}$. Basic electrophysiological parameters were then analyzed using whole-cell patch-clamp electrophysiology in acutely isolated brain slices. Cell capacitance was decreased in dopamine neurons from MitoPark mice $(\boldsymbol{C}, \boldsymbol{D})$. Dopaminergic neurons from MitoPark mice also exhibited an age-dependent increase in input resistance compared with littermate controls $(\boldsymbol{E}, \boldsymbol{F}) .{ }^{* *} p<0.01$, ${ }^{* * *} p<0.0001$.

the input resistance subsequent to a hyperpolarizing step from -55 to $-60 \mathrm{mV}$. Input resistance increased with age in dopaminergic neurons from MitoPark mice $\left(R^{2}=0.272, p<0.0001\right)$ but did not significantly change in neurons from controls $\left(R^{2}=\right.$ 0.0239, $p=0.0757$; Fig. $1 E$ ). A comparison of the slopes of the linear regression lines revealed a significant difference indicating an effect of genotype on input resistance across age $\left(F_{(1,271)}=\right.$ $271, p<0.0001)$. When data were organized into bins based on the age of the mice, a two-way ANOVA revealed that dopaminergic neurons from MitoPark mice exhibit significantly higher input resistances than controls that increased across age (main effect of genotype: $F_{(1,269)}=49.42, p<0.0001$; main effect of age: $F_{(2,269)}=21.44, p<0.0001$; age-genotype interaction, $F_{(2,269)}=$ 15.41, $p<0.0001)$; Holm-Sidak's multiple-comparisons tests, $p<0.0001$ for ages $16+$ weeks (Fig. $1 F$ ). These data suggest that dopaminergic neurons from MitoPark mice become smaller in size and exhibit reduced open ion channel activity resulting in higher input resistance concurrent with the neurodegenerative process.

\section{Spontaneous firing and associated conductances}

Dopaminergic neurons typically fire action potentials in a pacemaker-like fashion when examined in ex vivo brain slice preparations (Grace and Onn, 1989). Good et al. (2011) previously reported that 6- to 8-week-old MitoPark mice exhibited a wide range of firing frequencies. To study the effects of the MitoPark mutation on dopaminergic impulse activity across a range of ages we used the minimally invasive cell-attached configuration to examine basal firing properties of neurons from MitoPark and control mice (Fig. 2A,B). Firing rates from MitoPark mice increased with age $\left(R^{2}=0.125, p=0.0317\right)$ while firing rates in neurons from control mice did not differ over time $\left(R^{2}=\right.$ $0.0183, p=0.501)$. The slopes of the linear regression lines were significantly different $\left(F_{(1,60)}=5.36, p=0.024\right)$ indicating an effect of genotype on firing rate across age (Fig. 2C). In this case statistical tests run after splitting the data into age groups revealed no significant differences in firing rate, probably due to the highly variable firing rates in the MitoPark group (main effect of genotype: $F_{(1,58)}=1.21$, $p=0.275$; main effect of age: $F_{(2,58)}=$ $0.571, p=0.568$; age-genotype interaction: $F_{(2,58)}=0.971, p=0.385$; Fig. $\left.2 D\right)$. However, the rhythmicity of firing was visibly disrupted in many neurons from the MitoPark group; therefore, we next compared the consistency of the interspike intervals (time between spikes) within each cell by measuring the coefficient of variation (SD divided by the mean) and analyzing the logarithm of this value $[\log (\mathrm{CV}$ ISI)]. The variance of the interspike interval did not change over time in either the MitoPark or control mice $\left(R^{2}=0.00128, p=0.430 ; R^{2}=\right.$ $0.00706, p=0.480$, respectively; Fig. $2 E$ ). The slopes of the linear regression lines were also not different from each other $\left(F_{(1,58)}=0.0171\right.$, $p=0.896)$ but did exhibit different $y$-intercepts $\left(F_{(1,59)}=25.6\right.$, $p<0.0001)$. When data were grouped by age, two-way ANOVA revealed significantly more variance in the interspike interval in dopamine neurons from MitoPark mice ages 11 weeks and older (main effect of genotype: $F_{(1,56)}=10.24, p=0.0023$; main effect of age: $F_{(2,56)}=1.77, p=0.180$; age-genotype interaction: $F_{(2,56)}=1.13, p=0.33$; Holm-Sidak's multiple-comparison test significant at 11-15 and 16+ weeks; Fig. $2 F$ ). This suggests that pacemaker firing is not only variable across cells in MitoPark mice, but interspike intervals vary more within each cell. We also examined the width of the extracellular spike waveform in voltage-clamp mode from the initiation of the negative trough to the positive peak (Fig. 2G, blue line; Ford et al., 2006; Branch et al., 2014). We found that spike widths of dopamine neurons from MitoPark mice decreased with age $\left(R^{2}=0.292, p=0.0007\right)$ while spike widths did not change over time in control mice $\left(R^{2}=\right.$ $0.019, p=0.501$; Fig. $2 H$ ). The slopes of the lines between MitoPark and control mice were significantly different from each other indicating an effect of genotype across age $\left(F_{(1,58)}=7.51\right.$, $p=0.0082)$. When analyzed in bins, spike widths were narrower in dopamine neurons from MitoPark mice only at $16+$ weeks of age (two-way ANOVA; main effect of genotype: $F_{(1,56)}=17.39$, $p=0.0001$; main effect of age: $F_{(2,56)}=1.77, p=0.179$; agegenotype interaction: $F_{(2,56)}=5.46, p=0.0068$; Holm-Sidak's 


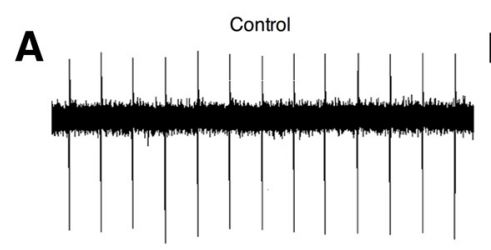

C
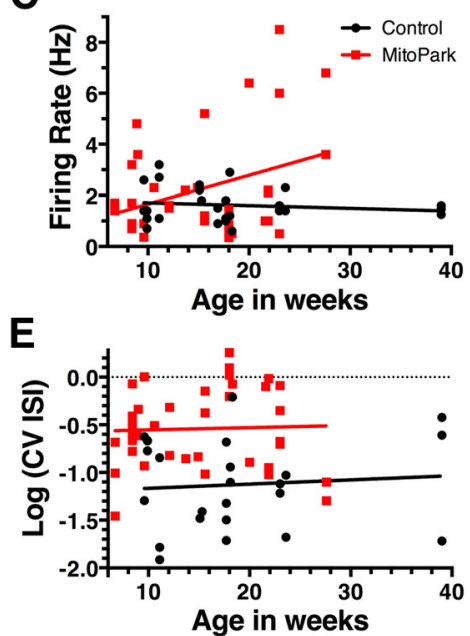

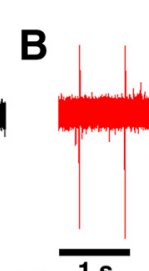

D
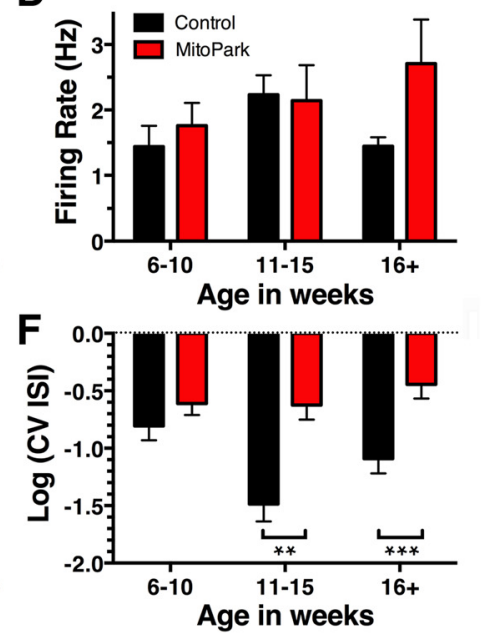

G

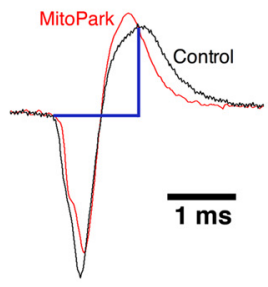

H
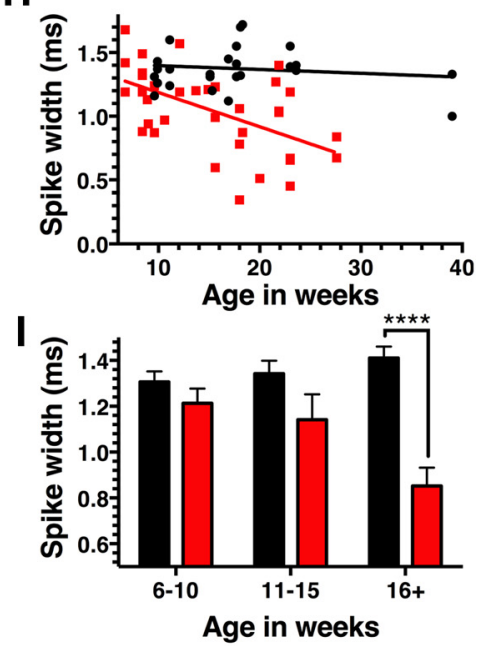

Figure 2. Pacemaker firing properties are altered in dopaminergic neurons from MitoPark mice. We performed loose cell-attached recordings to monitor the firing properties of dopaminergic neurons in brain slices from MitoPark and control mice. A sample trace $(\boldsymbol{A})$ from a 15.1-week-old control mouse is shown in contrast to a trace from a 12.4 -week-0ld MitoPark mouse $(\boldsymbol{B})$ that showed disrupted rhythmicity. Linear regression data indicated an elevation in firing rate with increasing age, with several neurons showing a dramatically higher firing rate in MitoPark mice ( $\boldsymbol{C}$. Firing rates did not significantly differ when data were pooled into age groups $(\boldsymbol{D})$. Single-cell data of the logarithm of the coefficient of variation of the interspike interval indicated elevated variability in the MitoPark mice that did not change with age $(\boldsymbol{E})$. When these data were grouped into bins based on mouse age, interspike intervals from MitoPark mice were significantly more variable at $11-15$ and $16+$ weeks of age $(\boldsymbol{F})$. The width of the extracellular waveforms was also calculated (G, blue line; sample traces from a 15.1-week-0ld control and a 15.6 week-old MitoPark mouse), and linear regression revealed an age-dependent decrease in MitoPark mice $(\boldsymbol{H})$. When grouped into bins, spike widths were significantly decreased in MitoPark mice $>16$ weeks of age $(\boldsymbol{I}) .{ }^{* *} p<0.01$, ${ }^{* * *} p<0.001,{ }^{* * * *} p<0.0001$.

multiple-comparison test, $p<0.0001$ for $16+$ weeks of age; Fig. $2 I)$. Together, these data indicate a deviation from characteristic pacemaker firing in MitoPark mice that becomes more pronounced with age and could indicate a significant marker of parkinsonian progression.

Because spontaneous firing of dopamine neurons is altered in the MitoPark mice and is strongly influenced by intrinsic conductances (Wolfart et al., 2001; Neuhoff et al., 2002), we next performed whole-cell experiments to examine two of the currents that contribute to pacemaker firing. We first analyzed the hyperpolarization-activated current $I_{\mathrm{h}}$ using a hyperpolarizing step from -55 to $-105 \mathrm{mV}$ (Fig. $3 A$ ) in control (Fig. $3 A$, middle) and MitoPark mice (Fig. $3 A$, bottom). This cation current is mediated by $\mathrm{HCN}$ channels and contributes to pacemaker firing fidelity in dopamine neurons (Neuhoff et al., 2002). Linear regression analysis showed that $I_{\mathrm{h}}$ did not change drastically across age in control mice $\left(R^{2}=0.0087, p=0.427\right)$ but neared significance in MitoPark mice $\left(R^{2}=0.0335, p=0.054\right)$. The slopes of the linear regression lines were however different indicating an effect of genotype across age $\left(F_{(1,181)}=4.08, p=0.04\right.$; Fig. $\left.3 B\right)$. Consistent with data previously obtained in 7-week-old mice (Good et al., 2011), two-way ANOVA of binned data indicated that $I_{\mathrm{h}}$ was smaller in neurons from MitoPark mice (main effect of genotype: $F_{(1,179)}=29.5, p<0.0001$; main effect of age: $F_{(2,179)}=1.60, p=0.204$; age-genotype interaction: $F_{(2,179)}=$ $0.508, p=0.602$; Holm-Sidak's multiple-comparison test significant at all age groups; Fig. 3C). We also applied a $100 \mathrm{~ms}$ depolarization step to $0 \mathrm{mV}$ (Fig. $3 D$, top) to induce an afterhyperpolarization current (AHC), which in dopaminergic neurons is largely dependent on small conductance calcium activated potassium (SK) channels (Wolfart et al., 2001; Ahn et al., 2010; Branch et al., 2014). Sample traces are shown for control (age 11.1 weeks old) and MitoPark mice (age 10.6 weeks old; Fig. $3 D$, middle and bottom, respectively). By analyzing the area under the curve (charge) beginning $20 \mathrm{~ms}$ after the termination of the depolarization step, we determined that the afterhyperpolarization does not change significantly across age in neurons from either MitoPark or control mice $\left(R^{2}=0.252, p=0.0566 ; R^{2}=\right.$ $0.0075, p=0.649$, respectively; Fig. $3 E$ ). However, although the slopes of the regression lines were not different from each other, $\left(F_{(1,41)}=0.917, p=0.34\right)$, there was a significant difference in $y$-intercepts $\left(F_{(1,42)}=8.99, p=0.0045\right)$ suggesting impaired SK currents in MitoPark mice. When analyzed in age brackets, MitoPark mice exhibited a smaller afterhyperpolarization than control mice (main effect of genotype: $F_{(1,39)}=9.36, p=0.004$; main effect of age: $F_{(2,39)}=1.72, p=0.192$; age-genotype interaction: $F_{(2,39)}=0.247, p=0.783$; Holm-Sidak's multiple-comparison test, $p<0.05$ at $6-10$ weeks and $16+$ weeks; Fig. $3 F)$.

To determine whether the decrease in $I_{\mathrm{h}}$ and afterhyperpolarization were secondary to the decrease in membrane surface area, data were normalized to cell capacitance to calculate current density for each recording. Two-way ANOVA of binned data indicated that $I_{\mathrm{h}}$ was smaller in neurons from MitoPark mice (main effect of genotype: $F_{(1,178)}=18.2, p<0.0001$; main effect of age: $F_{(2,178)}=4.05, p=0.0191$; age-genotype interaction: $F_{(2,178)}=$ $1.08, p=0.341$; Holm-Sidak's multiple-comparison test significant at all age groups, data not shown). Similarly, when AHC data were normalized to cell capacitance a two-way ANOVA of binned 

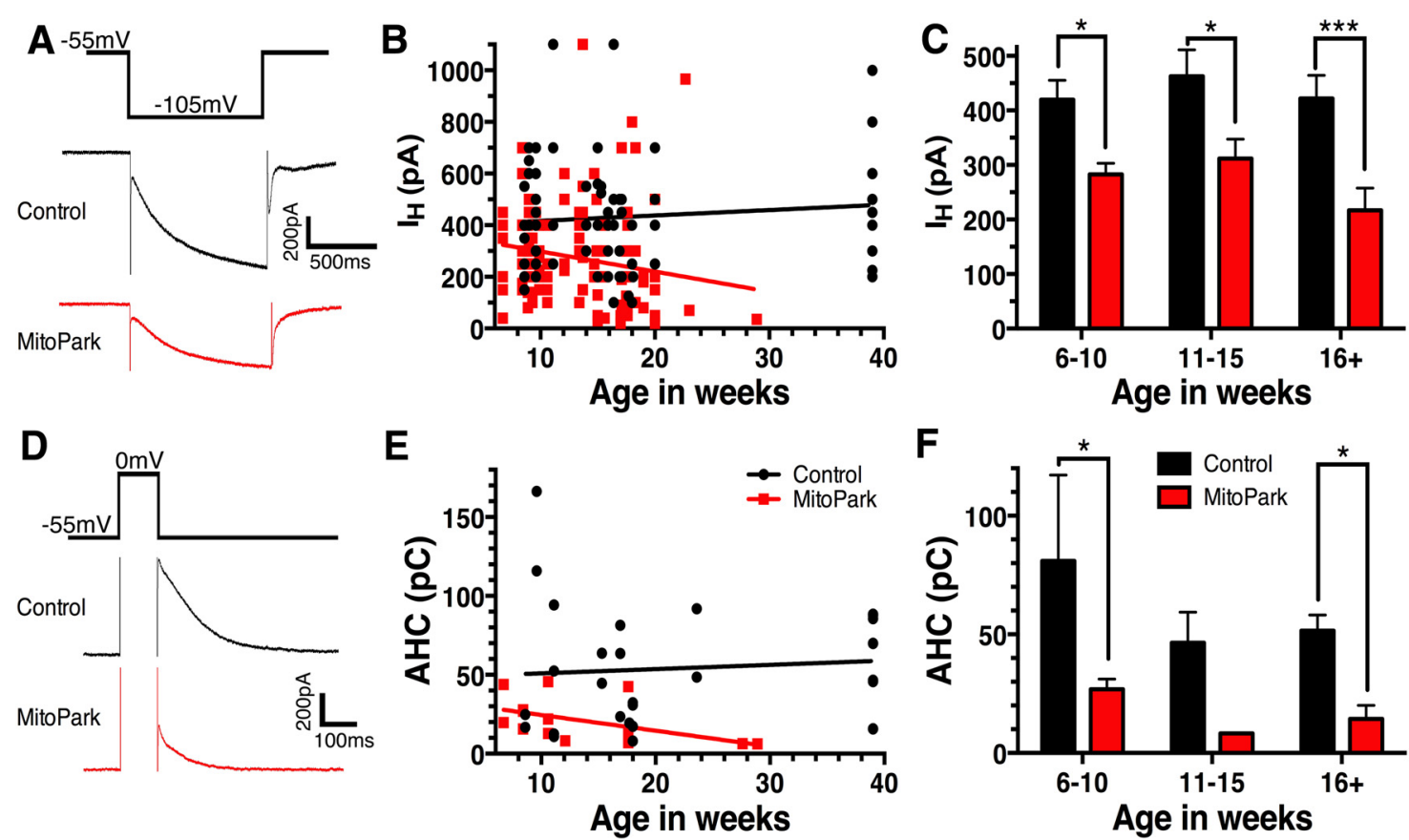

Figure 3. Slow intrinsic conductances are reduced in dopaminergic neurons from MitoPark mice. The HCN channel-mediated $I_{\mathrm{h}}$ was measured by applying a $1 \mathrm{~s} \mathrm{hyperpolarizing} \mathrm{step} \mathrm{from} \mathrm{-} 55$ to $-105 \mathrm{mV}(\boldsymbol{A})$. Dopaminergic neurons from MitoPark mice exhibited a globally lower $I_{\mathrm{h}}$ either when analyzed with linear regression $(\boldsymbol{B})$ or when data were grouped into bins $(\boldsymbol{C})$. The small conductance SK channel-mediated AHC was measured by applying a 100 ms depolarizing step from -55 to $0 \mathrm{mV}$ (D). Neurons from MitoPark mice exhibited lower area under the curve (charge) that did not depend on age $(\boldsymbol{E}, \boldsymbol{F}) .{ }^{*} p<0.05,{ }^{* * *} p<0.001$.

data indicated that current density was smaller in neurons from MitoPark mice (main effect of genotype: $F_{(1,33)}=5.42, p<0.026$; main effect of age: $F_{(2,33)}=0.243, p=0.786$; age-genotype interaction: $F_{(2,33)}=0.568, p=0.572$; Holm-Sidak's multiplecomparison test significant at all age groups, data not shown). These data suggest that alterations in HCN and SK channel conductances could contribute to aberrant dopamine neuron-firing characteristics in MitoPark mice, and that these effects are not secondary to decreased cell capacitance. A decrease in these ion channel conductances could have major implications for firing fidelity and the physiological consequences of dopamine release.

\section{Dendritic dopamine neurotransmission}

In addition to terminal projection fields, midbrain dopamine neurons synthesize and release dopamine in the somatodendritic compartment. Released dopamine can bind to D2 autoreceptors, activate G-protein-coupled potassium (GIRK) channels, and produce an outward current that can be measured electrophysiologically (Lacey et al., 1987; Beckstead et al., 2004). By measuring these currents we can study both the presynaptic and postsynaptic components of neurotransmission at dendrodendritic synapses between dopaminergic neurons (Wilson et al., 1977; Groves and Linder, 1983), ie, both dopamine release and dopamine receptor activation. We therefore examined D2 receptor-mediated outward currents in dopamine neurons from MitoPark and littermate controls across all ages. With the dopamine neuron voltage-clamped at $-55 \mathrm{mV}$, we first applied dopamine to the cell by iontophoresis for $2000 \mathrm{~ms}$ to determine the cell's maximum possible D2 receptor-mediated GIRK current (Fig. 4A). Linear regression analysis showed that D2 currents in dopamine neurons from both MitoPark and control mice did not differ with age $\left(R^{2}=0.130, p=0.0596 ; R^{2}=0.0348, p=0.220\right.$, respectively; Fig. $4 B$ ). The control group did show a trend toward increased currents with age, reflected as a significant difference between the slopes of the regression lines $\left(F_{(1,69)}=5.525, p=\right.$ 0.0216). When examined by age group, peak amplitudes of the outward current were larger in control mice than MitoPark mice, and this effect was enhanced with age (two-way ANOVA; main effect of genotype: $F_{(1,64)}=47.9, p=0.0001$; main effect of age: $F_{(2,64)}=2.09, p=0.132$; age- genotype interaction: $F_{(2,64)}=3.22$, $p=0.0467$; Holm-Sidak's multiple-comparison test, $p<0.0001$ at 11-15 weeks and $16+$ weeks of age; Fig. $4 C$ ). Lower inhibitory signaling in MitoPark mice could contribute to increased excitability, which would be a plausible adaptive mechanism to compensate for the progressive loss of dopaminergic neurons.

Next, we aimed to investigate the endogenous availability of the neurotransmitter dopamine in MitoPark mice. High concentrations of amphetamine increase extracellular dopamine concentrations as a consequence of substrate effects at the plasmalemmal dopamine transporter (DAT) and the vesicular monoamine transporter VMAT2 (Sulzer and Rayport, 1990; Sulzer et al., 1993; Jones et al., 1998). We performed whole-cell voltage-clamp recordings of dopaminergic neurons and induced efflux of dopamine by bath perfusing $30 \mu \mathrm{M}$ amphetamine. This produced an outward current that consistently peaked in $\sim 2 \mathrm{~min}$. When we observed that the current had plateaued for several seconds, we rapidly applied dopamine through iontophoresis to achieve the maximal outward current (Fig. 5A). We then compared the outward currents induced by amphetamine (ie, efflux of endogenous dopamine) to the total current induced by amphetamine + dopamine (Fig. 5B). Amphetamine-induced efflux of dopamine in neurons from control mice did not significantly change with age $\left(R^{2}=0.117, p=0.103\right)$, but did decrease with age in neurons from MitoPark mice $\left(R^{2}=0.433, p=0.0030\right)$. The slopes of the linear regression lines were significantly different from each other $\left(F_{(1,38)}=4.62, p=0.0381\right)$. When separated into age groups, the percentage of total outward current induced by amphetamine was smaller in dopamine neurons from MitoPark mice (two-way ANOVA; main effect of genotype: $F_{(1,36)}=35.8, p<0.0001$; main 
A

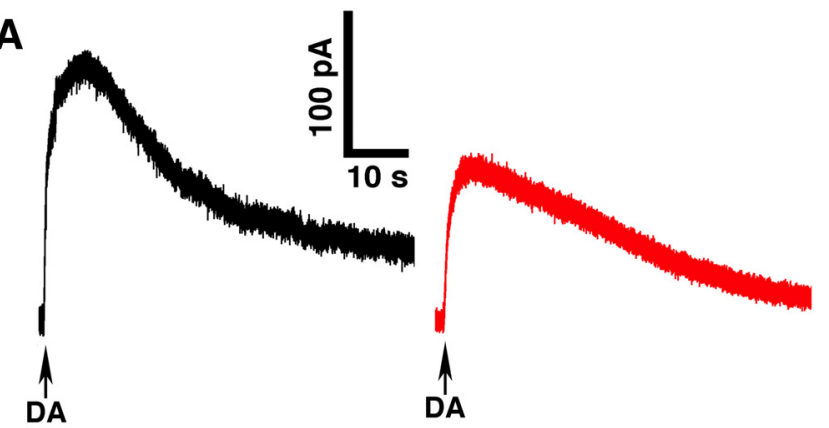

B
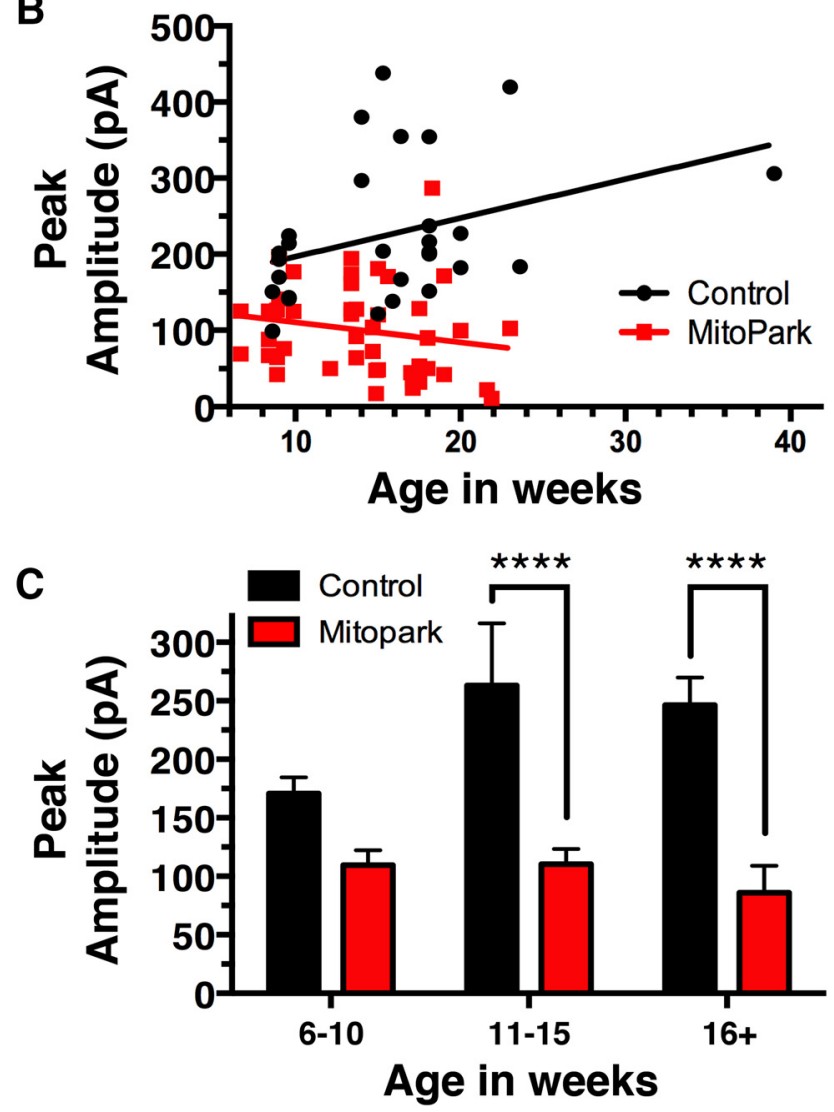

Figure 4. D2 dopamine autoreceptor-mediated currents are reduced in dopaminergic neurons from MitoPark mice. D2 receptor-mediated outward currents were measured in dopaminergic neurons from MitoPark and control mice by applying a maximally effective iontophoresis of dopamine. Sample traces from a control (16.4 weeks) and a MitoPark (15 weeks) mouse indicate smaller peak currents in neurons from MitoPark mice $(\boldsymbol{A})$. Dopamine neurons from MitoPark mice exhibited smaller peak currents across age compared with controls $(\boldsymbol{B})$, an effect that reached significance at ages $>11$ weeks $(\boldsymbol{C}){ }^{* * * *} p<0.0001$.

effect of age: $F_{(2,36)}=1.73, p=0.193$; age-genotype interaction: $F_{(2,36)}=3.05, p=0.060$; Holm-Sidak's multiple-comparison test significant at $6-10$ and $16+$ weeks of age; Fig. $5 C$ ). Notably, no measurable outward current was induced by amphetamine in neurons from MitoPark mice older than 16 weeks, indicating little to no endogenous availability of dopamine at an age where behavioral deficits start becoming evident.

To further investigate the condition of endogenous stores of dopamine in this mouse model, we electrically evoked the release of vesicular dopamine, producing an IPSC mediated through activation of somatodendritic D2 autoreceptors and GIRK channels (Beckstead et al., 2004; Fig. 6A). We evoked IPSCs over a
A

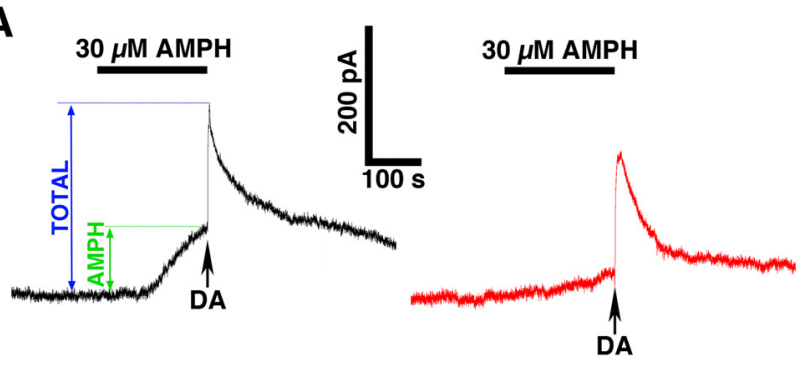

B
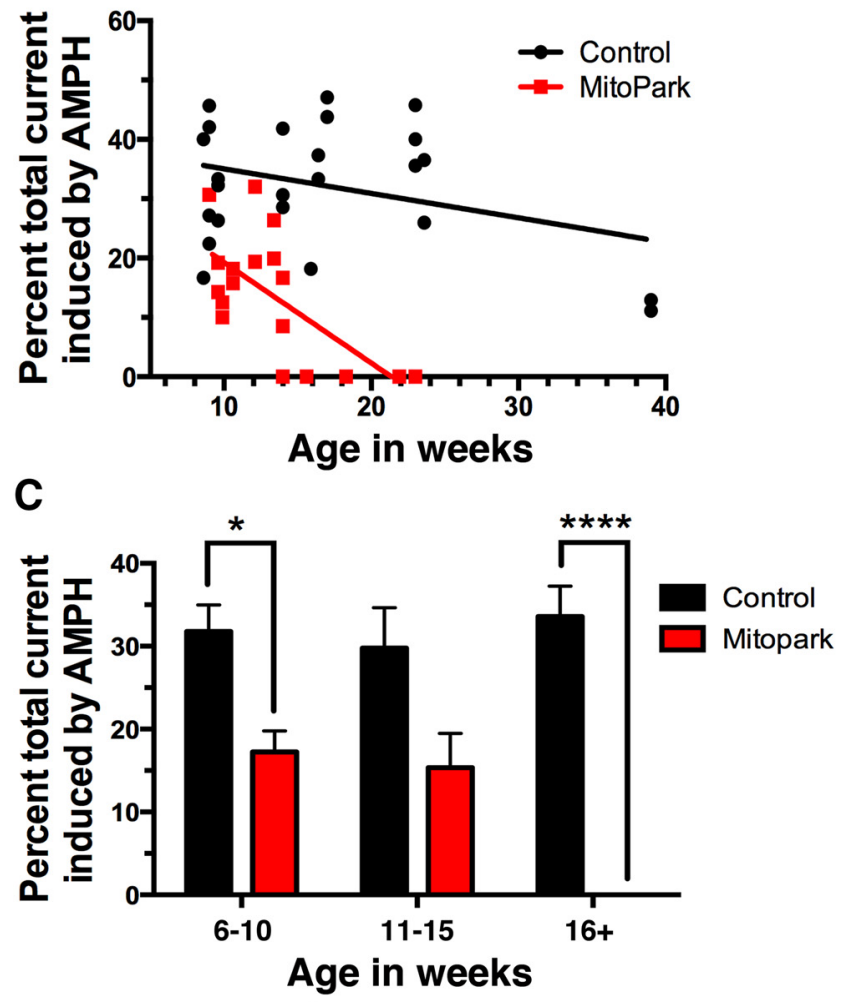

Figure 5. Amphetamine-induced currents are dramatically reduced in dopaminergic neurons from MitoPark mice. A large concentration $(30 \mu \mathrm{m})$ of amphetamine was applied to rapidly induce an outward current through dopamine efflux. After the outward current plateaued for several seconds, dopamine was applied by iontophoresis to achieve the maximum possible outward current. A sample trace ( $\boldsymbol{A}$, left) from a 23.6-week-old control mouse indicates how the amphetamine-induced outward current (green) was measured compared with the total D2 receptor-mediated current (blue). For comparison, a sample trace ( $\boldsymbol{A}$, right) is also shown from a 13.4-week-old MitoPark mouse. The amphetamine-induced currents were consistently smaller in recordings from MitoPark mice and decreased with age $(\boldsymbol{B})$. Amphetamine-induced currents were significantly smaller as early as $6-10$ weeks of age, and strikingly were eliminated by 16 weeks of age $(\boldsymbol{C}){ }^{*} p<0.05,{ }^{* * * *} p<0.0001$.

range of stimulus intensities in dopamine neurons from $\mathrm{Mi}$ toPark and control mice and IPSC amplitudes were measured at each intensity. IPSC amplitudes were smaller in neurons from MitoPark mice beginning at ages 6-10 weeks (main effect of genotype: $F_{(1,15)}=12.1, p=0.0034$; main effect of stimulus intensity: $F_{(3,45)}=24.76, p<0.0001$; stimulus intensity-genotype interaction: $F_{(3,45)}=10.19, p=0.0001$; Holm-Sidak's multiple-comparison test, significant at highest two intensities; Fig. $6 B$ ). Similar results were obtained from mice aged 11-15 weeks (main effect of genotype: $F_{(1,10)}=7.20, p=0.023$; main effect of stimulus intensity: $F_{(3,30)}=10.1, p<0.0001$; stimulus intensity-genotype interaction: $F_{(3,30)}=5.67, p=0.0034$; Fig. $6 C$ ) and $16+$ weeks (main effect of genotype: $F_{(1,11)}=7.40, p=$ 

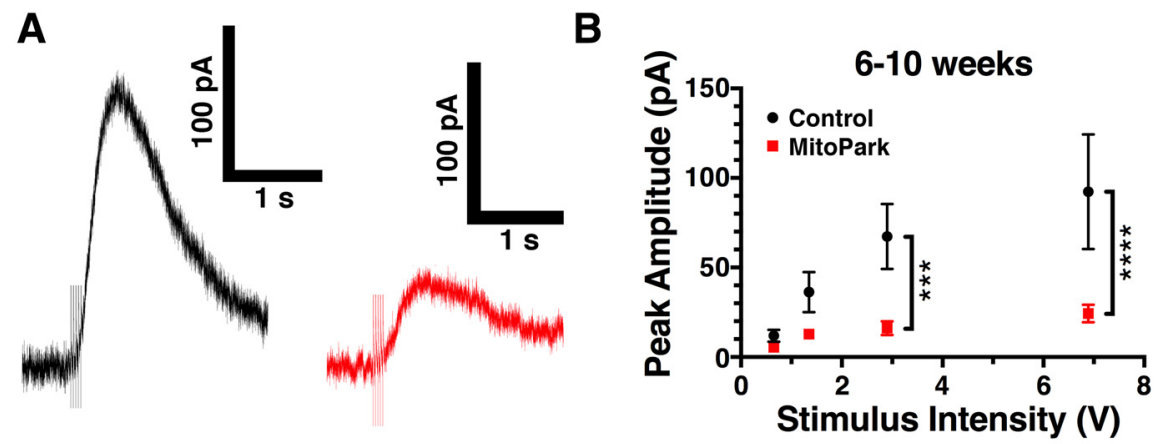

C

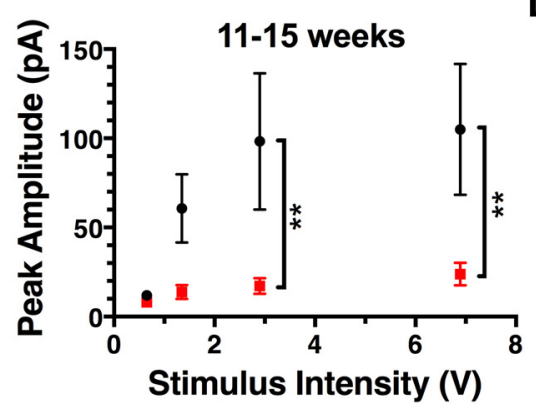

D

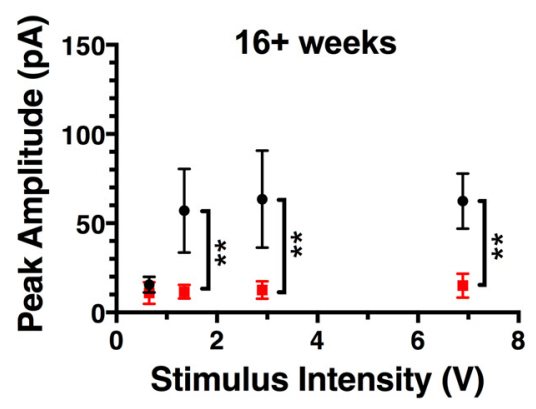

Figure 6. Dopaminergic neurons from MitoPark mice exhibit smaller dopamine-mediated IPSCS. IPSCs were electrically evoked using a bipolar stimulating electrode placed caudal to the target dopamine neuron in the presence of GABA, glutamate, and nicotinic acetylcholine receptor blockers. Sample traces $(\boldsymbol{A})$ are from a 14-week-old control mouse and a 13.4-week-old MitoPark mouse. Stimulus response curves were constructed with increasing stimulus intensities. At all age groups IPSCs from MitoPark mice were smaller as indicated by downward shift in the stimulus response curves $(\boldsymbol{B}-\boldsymbol{D}){ }^{* *} p<0.01,{ }^{* * *} p<0.001,{ }^{* * * *} p<0.0001$.

0.0199; main effect of stimulus intensity: $F_{(3,33)}=11.8, p<$ 0.0001 ; stimulus intensity-genotype interaction: $F_{(3,33)}=9.59$, $p=0.0001$; Fig. $6 D$ ). These data are consistent with a dramatic decrease in the availability in endogenous dopamine in MitoPark mice at ages that precede wholesale loss of dopaminergic neurons and overt behavioral symptomatology.

\section{Electrophysiological parameters in verified dopaminergic neurons}

Normally, electrophysiological identification of dopaminergic neurons of the $\mathrm{SN}$ in a mouse brain slice is straightforward, more so than (for instance) the rat ventral tegmental area (Margolis et al., 2010). However, our findings to this point indicated that the very electrophysiological parameters that we regularly use to identify dopaminergic neurons were actually reduced in recordings from MitoPark mice. Because the MitoPark mutation causes selective degeneration and death of dopaminergic neurons, it is also possible that our observed effects were merely a product of an increasing likelihood of recording from a non-dopaminergic neuron as the MitoPark mice aged and gross dopaminergic cell loss took hold. To determine whether this was the case, we conducted a separate experiment in 16.1- to 16.5-week-old MitoPark and control mice ( $n=3$ in each group). We sought to measure multiple electrophysiological parameters in each neuron, and couple that with immunohistochemical confirmation of TH expression (Fig. 7A). By filling the neurons at the time of recording with $0.2 \%$ neurobiotin (Vector Laboratories), we were able to identify 35 and 29 previously recorded neurons with immunostaining in the MitoPark and control groups, respectively. Of these neurons, 23 and 22 (66\% and 76\%) were, respectively, identified as being definitively $\mathrm{TH}+$ and their parameters were analyzed. Nearly all of the remainder of the neurons were excluded because their staining was inconclusive, likely due to a combina- tion of limitations including the thickness of the slices, the dense expression of $\mathrm{TH}$ signal in the $\mathrm{SN}$, and the established weakening of the TH signal in neurons that were recorded with whole-cell patchclamp (Zhang et al., 2010). One cell from the MitoPark group was clearly TH-.

Consistent with our previous findings, neurons from MitoPark mice that definitively co-stained for neurobiotin and $\mathrm{TH}$ exhibited decrease cell capacitance, increased input resistance, decreased $I_{\mathrm{h}}$ amplitude, decreased spike width, and decreased peak currents in response to iontophoresis of dopamine (Fig. $7 B-F$ ). Interestingly, $6 / 23$ (26.1\%) of the neurons in the MitoPark group exhibited a parameter (or in one case, 2 parameters) that under normal conditions would have caused us to terminate our recording under suspicion that the cell was not dopaminergic $\left(I_{\mathrm{h}}<100 \mathrm{pA}\right.$, spike width $<1.1$ $\mathrm{ms}$, or no outward current in response to iontophoresis of dopamine). These parameters did not appear to localize to the same neurons, as no cell exhibited both a narrow spike width and a small $I_{\mathrm{h}}$. Regardless, these results suggest that obtaining a minimum of two identifying characteristics may be necessary for satisfactory identification of $\mathrm{SN}$ neurons as dopaminergic when using a lightly characterized rodent model of disease.

\section{Gene expression}

Finally, we sought to determine whether genes associated with impulse activity of dopaminergic neurons are altered in MitoPark mice. We isolated brain tissue containing the $\mathrm{SN}$ from 18- to 22-week-old MitoPark and control mice and performed realtime quantitative RT-PCR. We observed a general trend toward upregulation of genes, including statistically significant increases of genes associated with Cav1.2, Cav1.3, HCN channels, and sodium channel subunits $\alpha 1.2$ and $\beta 3$ ( $n=6$ /group; Fig. $8 A$ ). To determine whether gene expression is changed at an age when behavioral symptoms are just beginning to emerge, we repeated the RT-PCR on 12-week-old MitoPark and control mice $(n=$ 8 /group). Of the five genes that were significantly increased in older mice, only the genes associated with Cav1.2 were significantly increased in the 12-week-old MitoPark mouse (Fig. 8B; $n=8$ /group). These results suggest that dopaminergic neurons may upregulate genes associated with spontaneous activity in a progressive fashion to preserve impulse activity when faced with mitochondrial damage. Interestingly, mRNA expression for the D2 dopamine receptor trended toward increase in 18- to 22week-old MitoPark mice $(p=0.09)$.

\section{Discussion}

\section{The MitoPark model of PD}

Presymptomatic detection of PD is of paramount importance as early intervention promises the best chance for halting, slowing, or reversing disease progression. Current treatments that target the dopamine system aim to alleviate PD symptoms but do not significantly alter the progression of neurodegeneration. Treatment options are often limited as most regimes begin after the onset of motor 
A
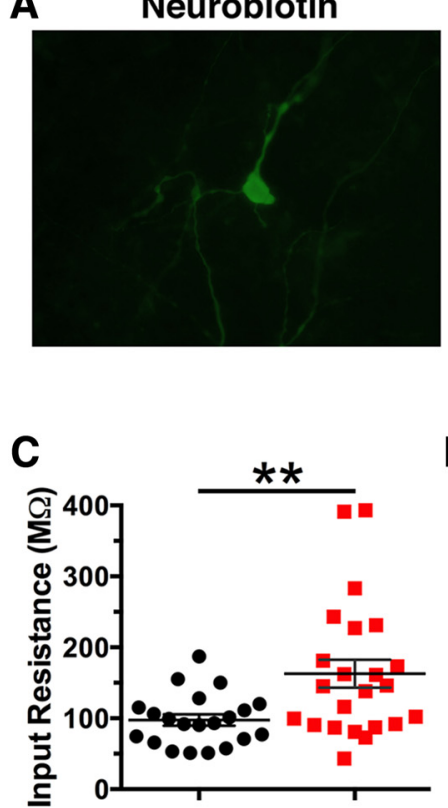

TH

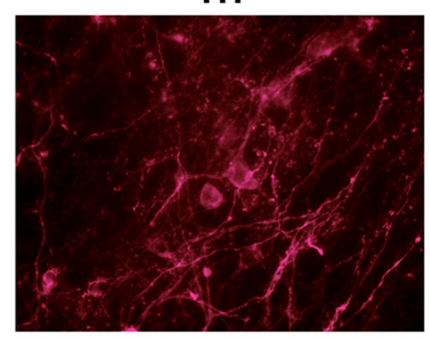

Merge

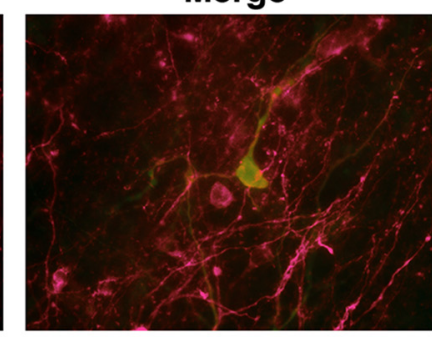

B

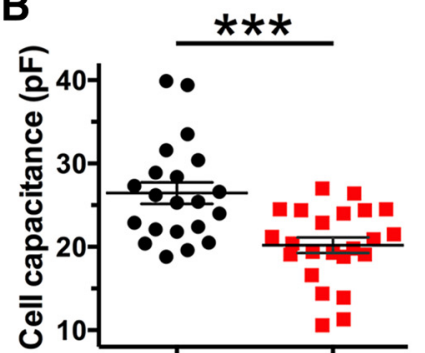

- Control - MitoPark

D

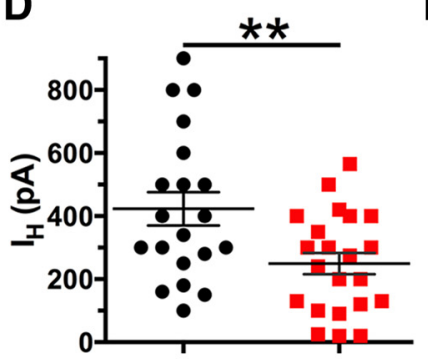

E

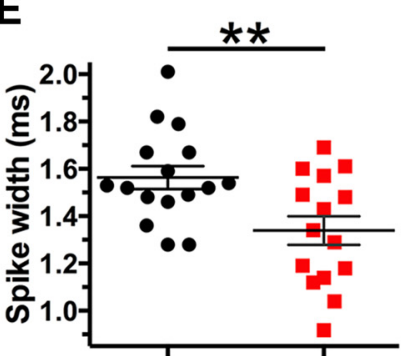

F

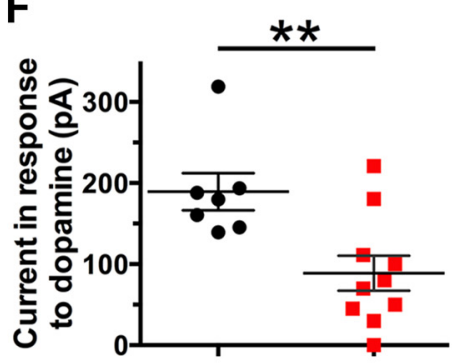

Figure 7. Verified tyrosine hydroxylase-positive neurons from MitoPark mice exhibit altered electrophysiological parameters. In a separate experiment, neurons were filled with $0.2 \%$ neurobiotin and recorded with an emphasis on obtaining multiple dependent electrophysiological measures from each cell. Cells were later stained ( $\boldsymbol{A}$ ) for neurobiotin (left) and TH (middle), and cells that definitively co-stained for both markers (right) were analyzed for their electrophysiological parameters. Consistent with previous results, recordings in neurons from MitoPark mice exhibited decrease cell capacitance $(\boldsymbol{B})$, increased input resistance $(\boldsymbol{C})$, and decreased $I_{\mathrm{h}}(\boldsymbol{D})$, spike width $(\boldsymbol{E})$, and peak current observed in response to iontophoresis of dopamine $(\boldsymbol{F})$. Two-tailed unpaired $t$ tests. ${ }^{* *} p<0.01,{ }^{* * *} p<0.001$.

impairments, a time point that is typically associated with a $50-60 \%$ loss of dopamine neurons. This suggests that disease pathogenesis and compensatory mechanisms are already well underway at the time of diagnosis (de la Fuente-Fernández et al., 2011).

MitoPark mice were engineered to lack the mitochondrial Tfam gene specifically in dopaminergic neurons. The Tfam gene is of nuclear origin but is vitally important for parameters affecting mitochondrial DNA such as transcription initiation, repair, and maintenance of copy number (Larsson et al., 1998; Ekstrand et al., 2004). The functional consequences of this genetic manipulation correspond to key characteristics of $\mathrm{PD}$ in humans including age-dependent loss of nigrostriatal dopaminergic neurons, motor impairments, response to L-DOPA treatment that worsens with time, development of inclusion bodies, decreased monoamine levels in the striatum, and mild cognitive impairment (Ekstrand et al., 2007; Galter et al., 2010; Li et al., 2013). Previously published work using the MitoPark model demonstrates that neuroadaptations, such as decreased striatal dopamine release, alteration of HCN channel currents, and decline of cognitive function occur before the onset of motor impairments (Good et al., 2011; Li et al., 2013). The current study describes the timeline for the electrophysiological adaptations that occur during progressive neurodegeneration in the MitoPark mouse.

Electrophysiological parameters of dopaminergic neurons We conducted an analysis of basal physiological parameters in dopaminergic neurons across ages in MitoPark mice and littermate controls. We observed higher input resistance and lower cell capacitance in neurons from MitoPark mice, both of which wors- ened with advancing age. Capacitance is directly related to membrane surface area, and since dendrites largely contribute to the membrane in midbrain dopaminergic neurons (Tepper et al., 1987; Wilson and Callaway, 2000; Jang et al., 2014) this finding may reflect a decrease in the extent of dendritic arborization. Voltage-gated ion channels are distributed in all subcellular compartments including the dendrites, thus, a diminished dendritic tree could also explain increased membrane resistance. Dendritic branching has not been quantified in MitoPark mice, however, a decrease in striatal innervation of dopamine neurons beginning at 12 weeks is consistent with a decline in neurite arborization (Ekstrand et al., 2007). Furthermore a reduction in SN dopamine neuron size may be of clinical importance in movement disorders; the Mecp2 mouse model of Rett syndrome (which is also a movement disorder) exhibits smaller soma size and shorter dendritic length than controls (Gantz et al., 2011; Panayotis et al., 
2011). Alterations in these parameters could have major implications for $\mathrm{PD}$ pathogenesis as membrane bound ion channels are critical determinants of resting membrane potential, propagation of graded potentials, and cell excitability. Treatment regimens that preserve dendritic ion channel participation could thus be beneficial in preserving basal firing properties needed to sustain dopamine neurotransmission.

Basal firing of SN neurons maintains extracellular levels of dopamine in projection regions that are essential for voluntary movement (Carli et al., 1985; Tepper et al., 1991). Changes in firing rate or pattern alter the amount of dopamine released both in terminal and somatodendritic compartments (Gonon and Buda, 1985; Rice et al., 2011). Previous work suggests that dopaminergic neurons in 6- to 8-week-old MitoPark mice can be classified into three distinct categories based on firing rate, and that low $I_{\mathrm{h}}$ amplitudes are present at this early age (Good et al., 2011). We similarly observed unusually variable firing rates and low HCN channel-mediated $I_{\mathrm{h}}$ amplitudes that worsened slightly with advancing age. Interspike intervals were also more variable in MitoPark mice, suggesting that the reliability of pacemaker firing is disrupted within individual neurons. MitoPark mice also exhibited small AHCs, which are largely mediated by SK channels. Although HCN and SK channels exert opposing effects on membrane potential at hyperpolarized voltages, both channels are responsible for a slow, voltage-sensitive conductance and contribute to the reliability of pacemaker firing (Shepard and Bunney, 1991; Wolfart et al., 2001; Neuhoff et al., 2002). An upset in the delicate balance of these ion conductances could largely contribute to firing pattern abnormalities and alter dopamine release in terminal regions that permits the initiation of voluntary movement.

\section{Presynaptic decline in dopamine release precedes postsynaptic decline in autoreceptor signaling}

The gold standard of PD treatment is chronic administration of the dopamine precursor L-DOPA (Birkmayer and Hornykiewicz, 1961), which is highly effective in initially relieving motor symptoms (Hauser, 2009). Because L-DOPA treatment directly targets and enhances dopaminergic neurotransmission, we sought to determine the presynaptic and postsynaptic adaptations in dopaminergic neurotransmission that occur in MitoPark mice. We accomplished this by measuring D2 autoreceptor-mediated outward currents in SN dopamine neurons. Currents induced by iontophoresis were approximately twofold smaller in recordings from MitoPark mice and worsened slightly with age, suggesting that D2 receptor signals could be a useful marker of disease progression.

We also examined dopamine currents elicited in response to release of endogenous dopamine and observed a severe early decrement in MitoPark mice. Electrical stimulation produced dopamine IPSCs that were dramatically smaller than littermate controls from an early age. This is consistent with experiments using other techniques to measure dopamine release in PD models, including electrochemical observations in the striatum of MitoPark mice (Scherfler et al., 2004; Goldberg et al., 2005; Kitada et al., 2007; Oyama et al., 2010; Good et al., 2011; Lundblad et al., 2012; Janezic et al., 2013). We used amphetamine as a tool to induce dopamine efflux (Sulzer and Rayport, 1990; Sulzer et al., 1993; Jones et al., 1998) and observed a dramatic decrement in MitoPark mice, and strikingly amphetamine was no longer capable of producing a detectable current by week 16. Dopamine action in the synapse can be affected by many parameters including dopamine transporters, vesicular release, and receptor feed- back systems. Reduced Vmat2 and Dat mRNA expression has been associated with PD (Harrington et al., 1996), and patients with idiopathic PD exhibit lower VMAT marker signals than what might be attributed to cell loss alone (Lee et al., 2000). Dopamine release could also be compromised by the decrease in spike width that we observed after 16 weeks in MitoPark mice. Regardless of mechanisms involved, our data indicate that the presynaptic decline in endogenous dopamine is more dramatic than, and likely precedes, decline of postsynaptic D2 receptor function.

\section{Ion channel subunit expression}

Older MitoPark mice exhibited increased expression of genes involved in pacemaker firing, which may reflect compensatory mechanisms that become active during neurodegeneration to help preserve neuronal function. The increase in HCN channel mRNA is in the opposite direction from our physiological observations of decreased $I_{\mathrm{h}}$ and is consistent with compensation to preserve neuronal firing. We also observed an increase in a sodium channel $(\mathrm{Scn} 2 \mathrm{a})$ that is important for the generation of action potentials (George, 2005) and a $\beta$ subunit $(\mathrm{Scn} 3 \mathrm{~b})$ that could modify the kinetics or voltage dependence of associated channels (Catterall et al., 2005). Finally, we observed upregulation of Cav1.2 and Cav1.3 channel subunits, which are responsible for the L-type calcium currents that play a large role in promoting pacemaker firing (Kang and Kitai, 1993; Wilson and Callaway, 2000). Interestingly, of the five genes significantly increased in older MitoPark mice, we only observed an increase in the gene associated with Cav1.2 at the 12 week time point. At 12 weeks, motor deficits are just beginning to emerge, and compensatory mechanisms may not yet be activated at the genetic level. We did not measure calcium channel-mediated currents in this study; however, increased calcium handling could predispose nigral neurons to oxidative damage and L-type calcium channel blockers are being actively investigated as therapeutics for PD (Guzman et al., 2010; Ilijic et al., 2011). The increased calcium channel gene expression is similar to the trend we observed in wild-type mice during normal aging (Branch et al., 2014), and aging is the leading risk factor for the development of PD (Collier et al., 2011). This effect (along with decreased spike width and increased variability of interspike intervals) is one of few that appear to thus far be common between our studies of dopaminergic neurons in MitoPark mice versus wild-type mice during normal aging (Branch et al., 2014).

In summary, our results indicate that dopaminergic neurons from MitoPark mice exhibit altered basal electrophysiological parameters and decrements in dopamine neurotransmission, pacemaker firing, and associated ion channel currents. These findings suggest that caution should be exercised when using electrophysiological parameters to classify neurons as dopaminergic when characterizing a new animal model of disease. Many observed effects were dependent on or worsened with age, but generally occurred before the timing of wholesale death of dopamine neurons and severe motor impairment. These early functional adaptations could potentially be useful as early markers of neurodegeneration or in developing treatment strategies during the early stages of PD in humans.

\section{References}

Ahn KC, Bernier BE, Harnett MT, Morikawa H (2010) IP3 receptor sensitization during in vivo amphetamine experience enhances NMDA receptor plasticity in dopamine neurons of the ventral tegmental area. J Neurosci 30:6689-6699. CrossRef Medline 
Beckstead MJ, Grandy DK, Wickman K, Williams JT (2004) Vesicular dopamine release elicits an inhibitory postsynaptic current in midbrain dopamine neurons. Neuron 42:939-946. CrossRef Medline

Birkmayer W, Hornykiewicz O (1961) The L-3,4-dioxyphenylalanine (DOPA)-effect in Parkinson-akinesia (in German). Wien Klin Wochenschr 73:787-788. Medline

Branch SY, Beckstead MJ (2012) Methamphetamine produces bidirectional, concentration-dependent effects on dopamine neuron excitability and dopamine-mediated synaptic currents. J Neurophysiol 108:802-809. CrossRef Medline

Branch SY, Sharma R, Beckstead MJ (2014) Aging decreases L-type calcium channel currents and pacemaker firing fidelity in substantia nigra dopamine neurons. J Neurosci 34:9310-9318. CrossRef Medline

Carli M, Evenden JL, Robbins TW (1985) Depletion of unilateral striatal dopamine impairs initiation of contralateral actions and not sensory attention. Nature 313:679-682. CrossRef Medline

Catterall WA, Goldin AL, Waxman SG (2005) International union of pharmacology: XLVII. Nomenclature and structure-function relationships of voltage-gated sodium channels. Pharmacol Rev 57:397-409. CrossRef Medline

Collier TJ, Kanaan NM, Kordower JH (2011) Ageing as a primary risk factor for Parkinson's disease: evidence from studies of non-human primates. Nat Rev Neurosci 12:359-366. CrossRef Medline

Dauer W, Przedborski S (2003) Parkinson's disease: mechanisms and models. Neuron 39:889-909. CrossRef Medline

Dawson TM, Ko HS, Dawson VL (2010) Genetic animal models of Parkinson's disease. Neuron 66:646-661. CrossRef Medline

de la Fuente-Fernández R, Schulzer M, Kuramoto L, Cragg J, Ramachandiran N, Au WL, Mak E, McKenzie J, McCormick S, Sossi V, Ruth TJ, Lee CS, Calne DB, Stoessl AJ (2011) Age-specific progression of nigrostriatal dysfunction in Parkinson's disease. Ann Neurol 69:803-810. CrossRef Medline

Duty S, Jenner P (2011) Animal models of Parkinson's disease: a source of novel treatments and clues to the cause of the disease. Br J Pharmacol 164:1357-1391. CrossRef Medline

Ekstrand MI, Galter D (2009) The MitoPark mouse: an animal model of Parkinson's disease with impaired respiratory chain function in dopamine neurons. Parkinsonism Relat Disord 15:S185-S188. CrossRef Medline

Ekstrand MI, Falkenberg M, Rantanen A, Park CB, Gaspari M, Hultenby K, Rustin P, Gustafsson CM, Larsson NG (2004) Mitochondrial transcription factor A regulates mtDNA copy number in mammals. Hum Mol Genet 13:935-944. CrossRef Medline

Ekstrand MI, Terzioglu M, Galter D, Zhu S, Hofstetter C, Lindqvist E, Thams S, Bergstrand A, Hansson FS, Trifunovic A, Hoffer B, Cullheim S, Mohammed AH, Olson L, Larsson NG (2007) Progressive Parkinsonism in mice with respiratory-chain-deficient dopamine neurons. Proc Natl Acad Sci U S A 104:1325-1330. CrossRef Medline

Ford CP, Mark GP, Williams JT (2006) Properties and opioid inhibition of mesolimbic dopamine neurons vary according to target location. J Neurosci 26:2788-2797. CrossRef Medline

Galter D, Pernold K, Yoshitake T, Lindqvist E, Hoffer B, Kehr J, Larsson NG, Olson L (2010) MitoPark mice mirror the slow progression of key symptoms and L-DOPA response in Parkinson's disease. Genes Brain Behav 9:173-181. CrossRef Medline

Gantz SC, Ford CP, Neve KA, Williams JT (2011) Loss of Mecp2 in substantia nigra dopamine neurons compromises the nigrostriatal pathway. J Neurosci 31:12629-12637. CrossRef Medline

George AL Jr (2005) Inherited disorders of voltage-gated sodium channels. J Clin Invest 115:1990-1999. CrossRef Medline

Goldberg MS, Pisani A, Haburcak M, Vortherms TA, Kitada T, Costa C, Tong Y, Martella G, Tscherter A, Martins A, Bernardi G, Roth BL, Pothos EN, Calabresi P, Shen J (2005) Nigrostriatal dopaminergic deficits and hypokinesia caused by inactivation of the familial Parkinsonism-linked gene DJ-1. Neuron 45:489-496. CrossRef Medline

Gonon FG, Buda MJ (1985) Regulation of dopamine release by impulse flow and by auto receptors as studied by in vivo voltammetry in the rat striatum. Neuroscience 14:765-774. CrossRef Medline

Good CH, Hoffman AF, Hoffer BJ, Chefer VI, Shippenberg TS, Bäckman CM, Larsson NG, Olson L, Gellhaar S, Galter D, Lupica CR (2011) Impaired nigrostriatal function precedes behavioral deficits in a genetic mitochon- drial model of Parkinson's disease. FASEB J 25:1333-1344. CrossRef Medline

Grace AA, Onn SP (1989) Morphology and electrophysiological properties of immunocytochemically identified rat dopamine neurons recorded in vitro. J Neurosci 9:3463-3481. Medline

Grauer SM, Hodgson R, Hyde LA (2014) MitoPark mice, an animal model of Parkinson's disease, show enhanced prepulse inhibition of acoustic startle and no loss of gating in response to the adenosine $\mathrm{A}(2 \mathrm{~A})$ antagonist SCH 412348. Psychopharmacology 231:1325-1337. CrossRef Medline

Greenamyre JT, Hastings TG (2004) Biomedicine: Parkinson's-divergent causes, convergent mechanisms. Science 304:1120-1122. CrossRef Medline

Groves PM, Linder JC (1983) Dendro-dendritic synapses in substantia nigra: descriptions based on analysis of serial sections. Exp Brain Res 49:209-217. Medline

Guzman JN, Sanchez-Padilla J, Wokosin D, Kondapalli J, Ilijic E, Schumacker PT, Surmeier DJ (2010) Oxidant stress evoked by pacemaking in dopaminergic neurons is attenuated by DJ-1. Nature 468:696-700. CrossRef Medline

Harrington KA, Augood SJ, Kingsbury AE, Foster OJ, Emson PC (1996) Dopamine transporter (Dat) and synaptic vesicle amine transporter (VMAT2) gene expression in the substantia nigra of control and Parkinson's disease. Brain Res Mol Brain Res 36:157-162. CrossRef Medline

Hauser RA (2009) Levodopa: past, present, and future. Eur Neurol 62:1-8. CrossRef Medline

Hornykiewicz O (1975) Parkinson's disease and its chemotherapy. Biochem Pharmacol 24:1061-1065. CrossRef Medline

Ilijic E, Guzman JN, Surmeier DJ (2011) The L-type channel antagonist isradipine is neuroprotective in a mouse model of Parkinson's disease. Neurobiol Dis 43:364-371. CrossRef Medline

Janezic S, Threlfell S, Dodson PD, Dowie MJ, Taylor TN, Potgieter D, Parkkinen L, Senior SL, Anwar S, Ryan B, Deltheil T, Kosillo P, Cioroch M, Wagner K, Ansorge O, Bannerman DM, Bolam JP, Magill PJ, Cragg SJ, Wade-Martins R (2013) Deficits in dopaminergic transmission precede neuron loss and dysfunction in a new Parkinson model. Proc Natl Acad Sci U S A 110:E4016-4025. CrossRef Medline

Jang J, Um KB, Jang M, Kim SH, Cho H, Chung S, Kim HJ, Park MK (2014) Balance between the proximal dendritic compartment and the soma determines spontaneous firing rate in midbrain dopamine neurons. J Physiol 592:2829-2844. CrossRef Medline

Jones SR, Gainetdinov RR, Wightman RM, Caron MG (1998) Mechanisms of amphetamine action revealed in mice lacking the dopamine transporter. J Neurosci 18:1979-1986. Medline

Kang Y, Kitai ST (1993) Calcium spike underlying rhythmic firing in dopaminergic neurons of the rat substantia nigra. Neurosci Res 18:195-207. CrossRef Medline

Kitada T, Pisani A, Porter DR, Yamaguchi H, Tscherter A, Martella G, Bonsi P, Zhang C, Pothos EN, Shen J (2007) Impaired dopamine release and synaptic plasticity in the striatum of PINK1-deficient mice. Proc Nat Acad Sci U S A 104:11441-11446. CrossRef Medline

Lacey MG, Mercuri NB, North RA (1987) Dopamine acts on D2 receptors to increase potassium conductance in neurons of the rat substantia nigra zona compacta. J Physiol 392:397-416. CrossRef Medline

Larsson NG, Wang J, Wilhelmsson H, Oldfors A, Rustin P, Lewandoski M, Barsh GS, Clayton DA (1998) Mitochondrial transcription factor A is necessary for mtDNA maintenance and embryogenesis in mice. Nat Genet 18:231-236. CrossRef Medline

Lee CS, Samii A, Sossi V, Ruth TJ, Schulzer M, Holden JE, Wudel J, Pal PK, de la Fuente-Fernandez R, Calne DB, Stoessl AJ (2000) In vivo positron emission tomographic evidence for compensatory changes in presynaptic dopaminergic nerve terminals in Parkinson's disease. Ann Neurol 47: 493-503. CrossRef Medline

Li X, Redus L, Chen C, Martinez PA, Strong R, Li S, O’Connor JC (2013) Cognitive dysfunction precedes the onset of motor symptoms in the MitoPark mouse model of Parkinson's disease. PLoS One 8:e71341. CrossRef Medline

Lin X, Parisiadou L, Gu XL, Wang L, Shim H, Sun L, Xie C, Long CX, Yang WJ, Ding J, Chen ZZ, Gallant PE, Tao-Cheng JH, Rudow G, Troncoso JC, Liu Z, Li Z, Cai H (2009) Leucine-rich repeat kinase 2 regulates the progression of neuropathology induced by Parkinson's-disease-related mutant alpha-synuclein. Neuron 64:807-827. CrossRef Medline

Lundblad M, Decressac M, Mattsson B, Björklund A (2012) Impaired neu- 
rotransmission caused by overexpression of $\alpha$-synuclein in nigral dopamine neurons. Proc Natl Acad Sci U S A 109:3213-3219. CrossRef Medline

Margolis EB, Coker AR, Driscoll JR, Lemaître AI, Fields HL (2010) Reliability in the identification of midbrain dopamine neurons. PLoS One 5:e15222. CrossRef Medline

Neuhoff H, Neu A, Liss B, Roeper J (2002) $I_{\mathrm{h}}$ channels contribute to the different functional properties of identified dopaminergic subpopulations in the midbrain. J Neurosci 22:1290-1302. Medline

Oyama G, Yoshimi K, Natori S, Chikaoka Y, Ren YR, Funayama M, Shimo Y, Takahashi R, Nakazato T, Kitazawa S, Hattori N (2010) Impaired in vivo dopamine release in parkin knockout mice. Brain Res 1352:214-222. CrossRef Medline

Panayotis N, Pratte M, Borges-Correia A, Ghata A, Villard L, Roux JC (2011) Morphological and functional alterations in the substantia nigra pars compacta of the Mecp2-null mouse. Neurobiol Dis 41:385-397. CrossRef Medline

Rice ME, Patel JC, Cragg SJ (2011) Dopamine release in the basal ganglia. Neuroscience 198:112-137. CrossRef Medline

Scherfler C, Khan NL, Pavese N, Eunson L, Graham E, Lees AJ, Quinn NP, Wood NW, Brooks DJ, Piccini PP (2004) Striatal and cortical pre- and postsynaptic dopaminergic dysfunction in sporadic parkin-linked parkinsonism. Brain 127:1332-1342. CrossRef Medline

Schober A (2004) Classic toxin-induced animal models of Parkinson's disease: 6-OHDA and MPTP. Cell Tissue Res 318:215-224. CrossRef Medline

Sharma R, Tsuchiya M, Skobe Z, Tannous BA, Bartlett JD (2010) The acid test of fluoride: how $\mathrm{pH}$ modulates toxicity. PLoS One 5:e10895. CrossRef Medline

Shepard PD, Bunney BS (1991) Repetitive firing properties of putative DA containing neurons in vitro: regulation by an apamin sensitive Ca activated K conductance. Exp Brain Res 86:141-150. Medline

Sulzer D, Rayport S (1990) Amphetamine and other psychostimulants reduce $\mathrm{pH}$ gradients in midbrain dopaminergic neurons and chromaffin granules: a mechanism of action. Neuron 5:797-808. CrossRef Medline

Sulzer D, Maidment NT, Rayport S (1993) Amphetamine and other weak bases act to promote reverse transport of dopamine in ventral midbrain neurons. J Neurochem 60:527-535. CrossRef Medline

Tepper JM, Sawyer SF, Groves PM (1987) Electrophysiologically identified nigral dopaminergic neurons intracellularly labeled with HRP: light-microscopic analysis. J Neurosci 7:2794-2806. Medline

Tepper JM, Creese I, Schwartz DH (1991) Stimulus-evoked changes in neostriatal dopamine levels in awake and anesthetized rats as measured by microdialysis. Brain Res 559:283-292. CrossRef Medline

Terzioglu M, Galter D (2008) Parkinson's disease: genetic versus toxininduced rodent models. FEBS J 275:1384-1391. CrossRef Medline

Wilson CJ, Callaway JC (2000) Coupled oscillator model of the dopaminergic neuron of the substantia nigra. J Neurophysiol 83:3084-3100. Medline

Wilson CJ, Groves PM, Fifková E (1977) Monoaminergic synapses, including dendro-dendritic synapses in the rat substantia nigra. Exp Brain Res 30:161-174. Medline

Wolfart J, Neuhoff H, Franz O, Roeper J (2001) Differential expression of the small-conductance, calcium-activated potassium channel SK3 is critical for pacemaker control in dopaminergic midbrain neurons. J Neurosci 21:3443-3456. Medline

Zhang TA, Placzek AN, Dani JA (2010) In vitro identification and electrophysiological characterization of dopamine neurons in the ventral tegmental area. Neuropharmacology 59:431-436. CrossRef Medline 